\title{
Physiological response to the six-minute walk test in pulmonary arterial hypertension
}

\author{
G. Deboeck*, G. Niset ${ }^{\#}$, J-L. Vachiery", J-J. Moraine ${ }^{\star}$ and R. Naeije*
}

ABSTRACT: The 6-min walk test (6MWT) is commonly used to evaluate exercise capacity in patients with pulmonary arterial hypertension (PAH). However, little is known about the corresponding metabolic stress as measured by cardiopulmonary exercise testing.

The present study, therefore, measured ventilatory variables and heart rate during the 6MWT and symptom-limited incremental maximal exercise testing in 20 patients with PAH.

The distance walked in $6 \mathrm{~min}$ was $450 \pm 22 \mathrm{~m}$ (mean $\pm \mathrm{SE}$ ). During the $6 \mathrm{MWT}$, ventilation, $\mathrm{O}_{2}$ consumption, $\mathrm{CO}_{2}$ production and heart rate increased during the first 3-4 min, and then remained stable. As compared with the maximum values measured during the cardiopulmonary exercise test, $\mathrm{O}_{2}$ consumption tended to be higher $\left(14.2 \pm 0.6\right.$ versus $\left.12.9 \pm 0.7 \mathrm{~mL} \cdot \mathrm{kg}^{-1} \cdot \mathrm{min}^{-1}\right)$, while maximum ventilation $\left(46 \pm 3\right.$ versus $\left.57 \pm 4 \mathrm{~L} \cdot \mathrm{min}^{-1}\right)$, respiratory quotient $(0.90 \pm 0.02$ versus $1.15 \pm 0.02)$ and heart rate $\left(119 \pm 4\right.$ versus $135 \pm 4$ beats $\left.\mathrm{min}^{-1}\right)$ remained lower.

In conclusion, patients with pulmonary arterial hypertension exercise at higher aerobic capacity and lower metabolic stress during the 6MWT than during a cardiopulmonary exercise test.

KEYWORDS: Cardiopulmonary exercise test, exercise, oxygen consumption, pulmonary arterial hypertension, six-minute walk test

$\mathbf{T}$ he 6-min walk test (6MWT) is commonly used for the evaluation of patients with cardiac or pulmonary diseases, as a form of submaximal exercise testing that is simple, reproducible, safe, inexpensive, applicable to everyday activities, sensitive to therapeutic interventions and of prognostic relevance [1, 2]. Accordingly, the 6MWT has been used as a primary endpoint in most randomised controlled trials of newly developed therapies in pulmonary arterial hypertension (PAH) [3]. However, the level of aerobic capacity and metabolic stress achieved during a 6MWT in PAH patients is not known exactly.

In patients with heart failure and in elderly subjects, oxygen uptake $\left(V^{\prime} \mathrm{O}_{2}\right)$ has been found to be consistently lower during the 6MWT than is achieved during a maximum bicycle cardiopulmonary bicycle exercise test (CPET) [4-6]. However, in patients with chronic obstructive pulmonary disease (COPD) maximum $V^{\prime} \mathrm{O}_{2}$ during the 6MWT has been reported to be equal to peak $V^{\prime} \mathrm{O}_{2}$ during a CPET, with lower ventilatory equivalents and respiratory exchange ratio (RER) [7]. There have been no data reported yet on the physiological response to the 6MWT in PAH. This is of particular relevance as there has been suggestion that, in these patients, the 6MWT may be more sensitive than CPET to therapeutic interventions [8].
Therefore, in this study, the ventilatory and gas exchange responses to the 6MWT were continuously measured in patients with $\mathrm{PAH}$, and the results were subsequently compared with those obtained during a standard incremental CPET.

\section{MATERIALS AND METHODS \\ Patients}

In total, 20 patients with PAH (16 females and four males; aged $53 \pm 3$ yrs (mean $\pm \mathrm{sE}$ ); height $165 \pm 2 \mathrm{~cm}$; and weight $69 \pm 4 \mathrm{~kg}$ ), were included in the study, which was approved by the Ethical Committee of the Erasme University Hospital (Brussels, Belgium). Each patient first performed a 6MWT followed by a CPET. It was reasoned that performing the 6MWT as a submaximal exercise test first would allow for more rapid and complete return of metabolic rate and associated ventilatory and haemodynamic variables to baseline. Accordingly, the exercise tests were performed consecutively and at least $2 \mathrm{~h}$ apart, with the patients in an initial stable state, as assessed by unchanged baseline $V^{\prime} \mathrm{O}_{2}$, carbon dioxide production $\left(V^{\prime} \mathrm{CO}_{2}\right)$, minute ventilation $\left(V^{\prime} \mathrm{E}\right)$ and heart rate.

The diagnosis of PAH rested on the demonstration of an increased pulmonary artery pressure in the presence of a normal pulmonary artery wedge pressure with no identifiable cardiac or pulmonary cause, either idiopathic or associated
AFFILIATIONS

*Dept of Physiology, Faculty of Medicine,

\#Dept of Cardiology, Erasme Hospital, and

"Dept of Physiology, Institute of Sports and Physiotherapy, Free University of Brussels, Belgium.

CORRESPONDENCE

R. Naeije

Laboratory of Physiology

Erasmus Campus

CP 604

Route de Lennik 808

B-1070 Brussels

Belgium

Fax: 3225554124

E-mail: rnaeije@ulb.ac.be

Received:

March 172005

Accepted after revision:

June 172005

SUPPORT STATEMENT

This study was supported by grant number 3.4516 .02 from the Fonds de la Recherche Scientifique Médicale and by the Foundation for Cardiac Surgery, Belgium. 
with a series of conditions, including the intake of appetite suppressants, connective tissue disease, liver cirrhosis, HIV infection or congenital left-to-right shunts [9]. PAH was idiopathic in six of the patients, and associated with intake of fenfluramines in five, connective tissue disease without significant lung function impairment in three, portal hypertension in two and congenital left-to-right cardiac shunt with secondary shunt reversal (Eisenmenger syndrome) in four. At right heart catheterisation, mean pulmonary artery pressure was $57 \pm 8 \mathrm{mmHg}$, pulmonary artery wedge pressure $9 \pm 1 \mathrm{mmHg}$ and cardiac index $2.5 \pm 0.2 \mathrm{~L} \cdot \mathrm{min}^{-1} \cdot \mathrm{m}^{-2}$. Resting heart rate was $83 \pm 2$ beats $\cdot \mathrm{min}^{-1}$ and blood pressure (systolic/ diastolic) $120 \pm 3 / 71 \pm 2 \mathrm{mmHg}$. Two of the patients were in New York Heart Association (NYHA) functional class I, 11 in NYHA class II and seven in NYHA class III. The patients were treated with anticoagulants $(n=14)$, calcium channel blockers $(n=3)$, diuretics $(n=12)$, subcutaneous treprostinil $(n=5)$, bosentan $(n=8)$, sitaxsentan $(n=4)$ and treprostinil combined with bosentan $(n=1)$.

\section{Six-minute walk test}

The measurement of distance walked in 6 min was performed in all the patients according to a standardised protocol [10]. The patients were instructed to walk back and forth at their own pace along a 35-m corridor to cover as much ground possible in the allotted time. A research assistant supervised the test, telling the patient the remaining exercise time every $2 \mathrm{~min}$. The patients were allowed to stop and take a rest during the test, but were instructed to resume walking as soon as possible. However, no patient who stopped during the 6MWT was included in the study. All the patients had previously performed a $6 \mathrm{MWT}$ as part of their routine follow-up. To control for any residual learning effect, the second of two tests performed on at least 2 separate days was used for the present study. Dyspnoea during the test was evaluated with the modified Borg dyspnoea score [11]. The work of walk $\left(\mathrm{W}_{\mathrm{w}}\right)$ was calculated as the product of distance walked multiplied by body weight [12].

During the $6 \mathrm{MWT}, V^{\prime} \mathrm{O}_{2}, V^{\prime} \mathrm{CO}_{2}$ and $V^{\prime} \mathrm{E}$ were continuously measured using a portable telemetric system. (Oxycon Mobile; Viasys Healthcare, Hoechberg, Germany). The patients breathed through a tightly fitted facemask with minimal dead space $(<30 \mathrm{~mL}$ ). The device (which weighed $0.95 \mathrm{~kg}$ ) was attached to the patient with a harness system, which slipped over the shoulders allowing the patients to move freely without discomfort. The data could be continuously checked for quality on-line through radio transmission and display on a personal computer located at one end of the corridor. The gas analysers and turbine were calibrated before each test.

\section{Maximal CPET}

The CPET was performed in an erect position on an electronically braked cycle ergometer with breath-by-breath measurements taken of $V^{\prime} \mathrm{E}, V^{\prime} \mathrm{O}_{2}$, and $V^{\prime} \mathrm{CO}_{2}$ using a fixed cardiopulmonary exercise system (Vmax; SensorMedics, Yorba Linda, CA, USA) through a tightly fitted facial mask. After $2 \mathrm{~min}$ at $0 \mathrm{~W}$, the work-rate was increased by $10 \mathrm{~W} \cdot \mathrm{min}^{-1}$. Peak $V^{\prime} \mathrm{O}_{2}$ was defined as the $V^{\prime} \mathrm{O}_{2}$ measured during the last $20 \mathrm{~s}$ of peak exercise. Oxygen pulse was calculated by dividing $V^{\prime} \mathrm{O}_{2}$ by heart rate. The ventilatory equivalents for $\mathrm{CO}_{2}\left(V^{\prime} \mathrm{E} / V^{\prime} \mathrm{CO}_{2}\right)$ were calculated by dividing $V^{\prime} \mathrm{E}$ by $V^{\prime} \mathrm{CO}_{2}$. The anaerobic threshold was estimated using the V-slope method [13].

\section{Additional measurements}

Heart rate was measured using a continuously monitored electrocardiogram and arterial oxygen saturation $\left(\mathrm{Sp}, \mathrm{O}_{2}\right)$ measured by pulse oximetry (Nonin 8500 M; Nonin Medical, Minneapolis, MN, USA) during both exercise tests.

\section{Comparison of the two ergospirometric devices}

The agreement between the portable Oxycon Mobile telemetric system and the fixed cardiopulmonary exercise system was checked in nine healthy young adult subjects. These subjects performed a CPET with each device in a random order and on 2 different days. Stable initial state was assessed by unchanged baseline $V^{\prime} \mathrm{O}_{2}, V^{\prime} \mathrm{CO}_{2}, V^{\prime} \mathrm{E}$ and heart rate, and with measurements compared at 25, 50, 75 and $100 \%$ of their maximum workload.

\section{Statistics}

Results were expressed as mean \pm SE. Paired t-tests were used to compare the ventilatory variables, heart rate and $S \mathrm{p}, \mathrm{O}_{2}$ achieved during the 6MWT and the CPET. ANOVA (repeated measures) was used to analyse the physiological profile throughout the 6MWT [14]. Correlations were calculated by linear regression analysis. The agreement between devices was evaluated by a Bland and Altman analysis [15].

\section{RESULTS \\ Comparison of the telemetric and fixed ergospirometric devices}

There were no significant differences in $V^{\prime} \mathrm{O}_{2}, V^{\prime} \mathrm{CO}_{2}$, and $V^{\prime} \mathrm{E}$ measured using the telemetric and fixed ergospirometric devices. The correlations between ventilatory variables measured by both devices were as follows: $V^{\prime} \mathrm{O}_{2}: \mathrm{r}=0.9847 ; V^{\prime} \mathrm{CO}_{2}$ : $\mathrm{r}=0.9844$; and $V^{\prime} \mathrm{E}: \mathrm{r}=0.9763$ (fig. 1). Over the range of ventilatory variables measured in the $\mathrm{PAH}$ patients there were no significant differences between linear regressions and line of identity between ventilatory variables measured by both devices. With the Bland-Altman test, the mean $V^{\prime} \mathrm{O}_{2}$ difference was $2 \mathrm{~mL} \cdot \mathrm{min}^{-1}$ and the limits of agreement (mean $\pm \mathrm{SD}$ ) were $165--160 \mathrm{~mL} \cdot \mathrm{min}^{-1}$. The bias for $V^{\prime} \mathrm{CO}_{2}$ and $V^{\prime} \mathrm{E}$ were comparatively small.

\section{Physiological responses to the 6MWT}

The distance walked in $6 \mathrm{~min}$ was $450 \pm 22 \mathrm{~m}$, with a Borg score of $4.5 \pm 2.0$. As shown in figures $2-4$, ventilation, $V^{\prime} \mathrm{CO}_{2}$, $V^{\prime} \mathrm{O}_{2}$ and heart rate increased during the first $3 \mathrm{~min}$ of the $6 \mathrm{MWT}$, and then remained stable. $\mathrm{O}_{2}$ pulse was already stable by the 2nd $\min . V^{\prime} \mathrm{E} / V^{\prime} \mathrm{CO}_{2}$ increased in the 1 st min, then returned to baseline value and remained constant. $S \mathrm{p}, \mathrm{O}_{2}$ decreased during the first $2 \mathrm{~min}$, then remained stable at $76 \%$. The walking speed remained, on average, constant during the entire $6 \mathrm{MWT}$.

As shown in table 1 , the $\mathrm{W}_{\mathrm{w}}$ was closely correlated to plateau $V^{\prime} \mathrm{O}_{2}$, accounting for $82 \%$ of its variance. Body weight and the distance walked in $6 \mathrm{~min}$ were correlated to plateau $V^{\prime} \mathrm{O}_{2}$ as well, but less tightly. The $\mathrm{W}_{\mathrm{w}}$ and distance walked in $6 \mathrm{~min}$ were also correlated to CPET peak $V^{\prime} \mathrm{O}_{2}$, but less tightly than to $6 \mathrm{MWT}$ plateau $V^{\prime} \mathrm{O}_{2}$. 

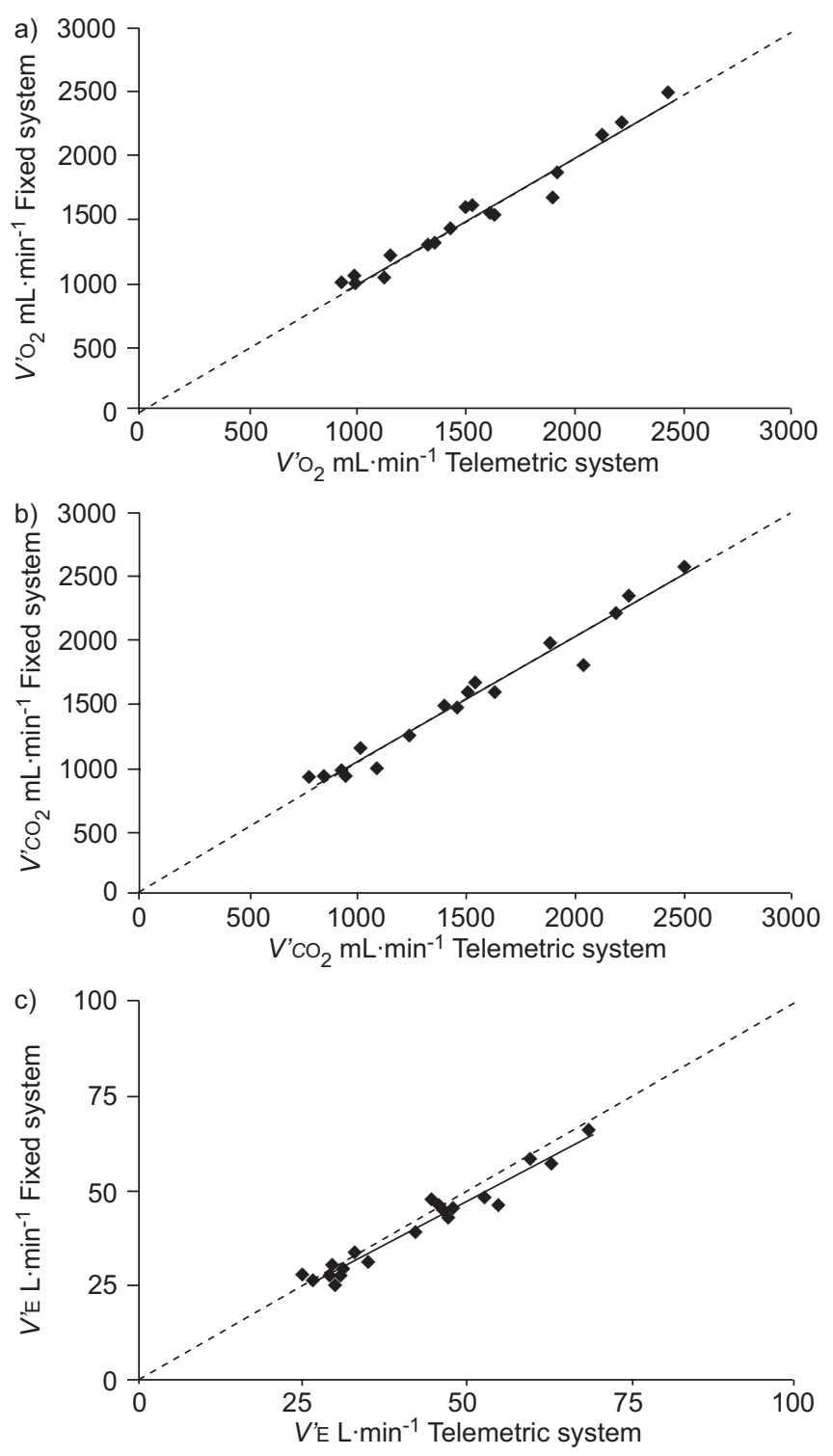

FIGURE 1. Scatter plots showing the high correlation between the measurements made with the fixed and the telemetric ergospirometric devices. The data points were distributed around the line of identity (- - ), which was not different from the regression line (-). a) $r=0.9847, b) r=0.9844$ and c) $r=0.9763$. $V^{\prime} O_{2}$ : oxygen uptake; $V^{\prime} \mathrm{CO}_{2}$ : carbondioxide output; $V^{\prime} \mathrm{E}$ : minute ventilation.

\section{MWT compared with CPET}

Table 2 shows ventilatory variables, $\mathrm{Sp}, \mathrm{O}_{2}$, heart rate and $\mathrm{O}_{2}$ pulse achieved during the last minute of a $6 \mathrm{MWT}$ and a CPET. The workload achieved during the CPET was $58 \pm 5 \mathrm{~W} . V^{\prime} \mathrm{O}_{2}$ measured during the last minute of the $6 \mathrm{MWT}$ tended to be higher than peak $V^{\prime} \mathrm{O}_{2}$, while $V^{\prime} \mathrm{E}, V^{\prime} \mathrm{CO}_{2}$, RER and heart rate remained lower. $S \mathrm{p}, \mathrm{O}_{2}$ decreased more during the $6 \mathrm{MWT}$. Plateau $V^{\prime} \mathrm{E} / V^{\prime} \mathrm{CO}_{2}$ during the walk was equivalent to the $V^{\prime} \mathrm{E} /$ $V^{\prime} \mathrm{CO}_{2}$ at the anaerobic threshold of the CPET. Plateau $\mathrm{O}_{2}$ pulse was greater during the $6 \mathrm{MWT}$.

\section{PAH categories}

The four patients with PAH and right-to-left shunts presented with more severe exercise-induced hypoxaemia. Accordingly, the omission of these four patients from the global patient

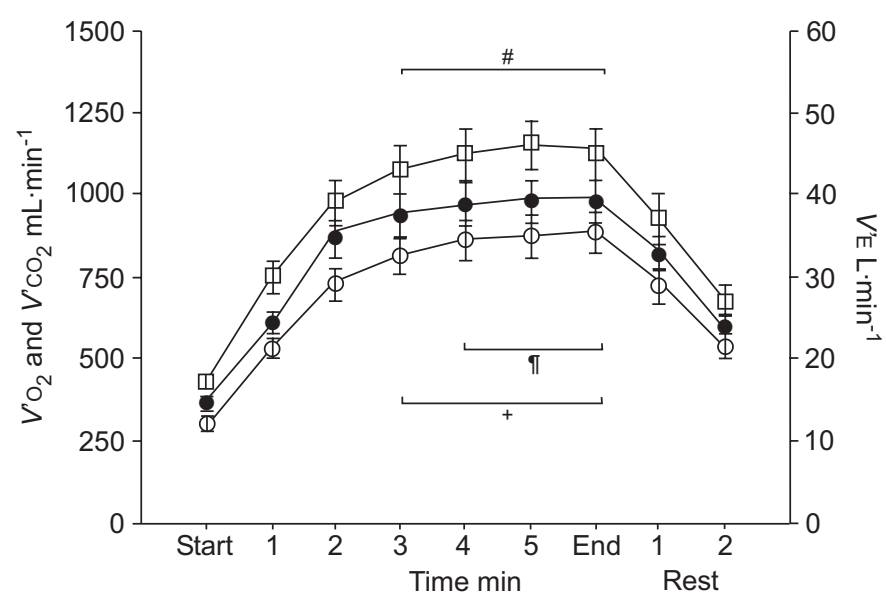

FIGURE 2. Oxygen uptake $\left(V^{\prime} \mathrm{O}_{2} ; \bullet\right)$ carbon dioxide output $\left(\mathrm{V}^{\prime} \mathrm{CO}_{2} ; \mathrm{O}\right)$ and minute ventilation ( $\left.V^{\prime} \mathrm{E} ; \square\right)$ during the 6 -min walk test in 20 patients with pulmonary arterial hypertension. A steady state for these ventilatory variables was achieved after 3-4 min. *: V'E $p=0.59 ;{ }^{+}: V^{\prime} O_{2} p=0.56 ;{ }^{\circ}: V^{\prime} \mathrm{CO}_{2} \mathrm{p}=0.23$.

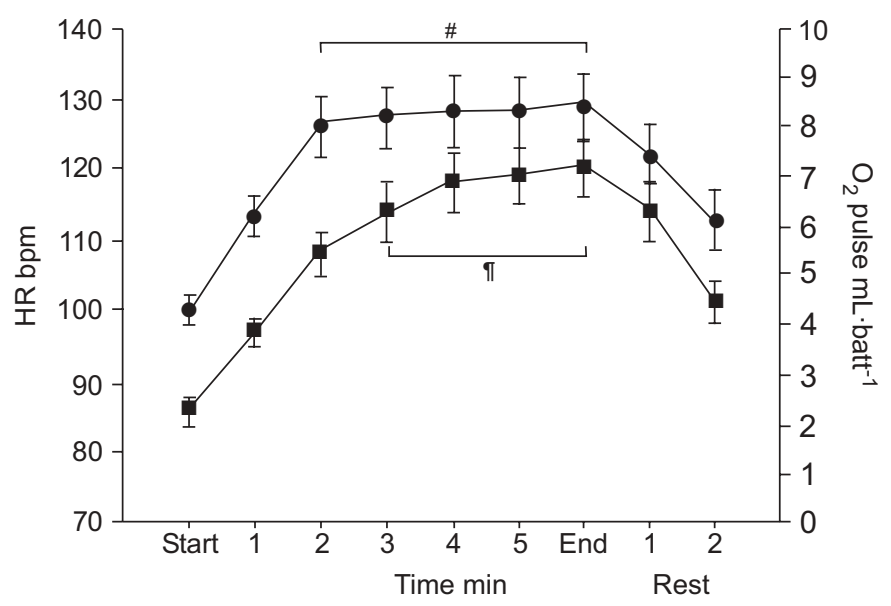

FIGURE 3. Heart rate ( $\mathrm{HR} ; \boldsymbol{\square})$ and oxygen pulse $\left(\mathrm{O}_{2}\right.$ pulse; $\bullet$ ) during the 6 min walk test in 20 patients with pulmonary arterial hypertension. A steady state was achieved after 2-3 min. \#: $p=0.15 ;$ ๆ: $p=0.53$. $\quad V^{\prime} O_{2}$ : oxygen uptake; $V^{\prime} \mathrm{CO}_{2}$ : carbondioxide output; V'E: minute ventilation.

population limited the decrease in $\mathrm{Sp}_{\mathrm{p}} \mathrm{O}_{2}$ to $82 \pm 2 \%$ instead of $75 \pm 4 \%$ at the end of the $6 \mathrm{MWT}$, and to $90 \pm 1$ instead of $86 \pm 2 \%$ at the end of the CPET. However, this did not affect the results on $V^{\prime} \mathrm{O}_{2}, V^{\prime} \mathrm{CO}_{2}, V^{\prime} \mathrm{E}$ and heart rate. The $S \mathrm{p}, \mathrm{O}_{2}$ measurements in the three patients with connective tissue-associated PAH did not appear to differ from the $\mathrm{Sp}, \mathrm{O}_{2}$ measurements in the other $\mathrm{PAH}$ patients without left-to-right shunts. Accordingly, omission of these three patients from the global patient population did not affect the results on $V^{\prime} \mathrm{O}_{2}, V^{\prime} \mathrm{CO}_{2}, V^{\prime} \mathrm{E}$ and heart rate.

\section{DISCUSSION}

The present results show that PAH patients perform a $6 \mathrm{MWT}$ at relatively higher aerobic capacity and lower metabolic stress than achieved during a standard CPET.

During the 6MWT, the patients were in a steady state from 2 3 min after the start, as assessed by stable $V^{\prime} \mathrm{O}_{2}, V^{\prime} \mathrm{E} / V^{\prime} \mathrm{CO}_{2}$, 


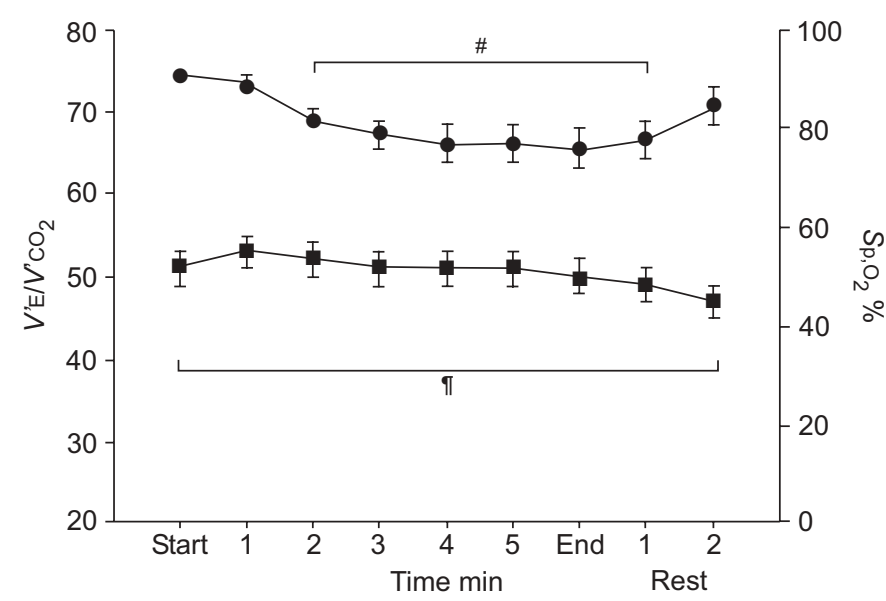

FIGURE 4. Ventilatory equivalent for carbon dioxide output $\left(V^{\prime} E / V^{\prime} \mathrm{CO}_{2}\right.$; arterial oxygen saturation measured by pulse oximetry $\left(\mathrm{Sp}_{\mathrm{O}} \mathrm{O}_{2} ; \boldsymbol{\bullet}\right)$ during the 6 -min walk test in 20 patients with pulmonary arterial hypertension. $V^{\prime} \mathrm{E} / \mathrm{V}^{\prime} \mathrm{CO}_{2}$ essentially remained stable, while $S p, O_{2}$ decreased during the first 2 min. ${ }^{\#}: p=0.5 ;{ }^{\circ}: p=0.61$.

\begin{tabular}{|c|c|c|c|}
\hline TABLE 1 & \multicolumn{3}{|c|}{$\begin{array}{l}\text { Correlations achieved during the 6-min walk test } \\
(6 \mathrm{MWT}) \text { and cardiopulmonary exercise test } \\
\text { (CPET) in } 20 \text { pulmonary arterial hypertension } \\
\text { patients }\end{array}$} \\
\hline Correlation & & $\mathbf{r}$ & $\mathbf{R}^{2}$ \\
\hline \multicolumn{2}{|c|}{$W_{\mathrm{w}}-V^{\prime} \mathrm{O}_{2} \mathrm{~mL} \cdot \mathrm{min}^{-1} 6 \mathrm{MWT}$} & 0.9066 & 0.8219 \\
\hline \multicolumn{2}{|c|}{$\mathrm{W}_{\mathrm{w}-\text { peak }} \mathrm{V}^{\prime} \mathrm{O}_{2} \mathrm{~mL} \cdot \mathrm{min}^{-1}$} & 0.7317 & 0.5353 \\
\hline \multicolumn{2}{|c|}{ Dist.- $V^{\prime} \mathrm{O}_{2} \mathrm{~mL} \cdot \mathrm{min}^{-1} 6 \mathrm{MWT}$} & 0.5252 & 0.2758 \\
\hline \multicolumn{2}{|c|}{ Dist.-peak $V^{\prime} \mathrm{O}_{2} \mathrm{~mL} \cdot \mathrm{min}^{-1}$} & 0.2761 & 0.0762 \\
\hline \multicolumn{2}{|c|}{ Dist. $-V^{\prime} \mathrm{O}_{2} \mathrm{~mL} \cdot \mathrm{min}^{-1} \cdot \mathrm{kg}^{-1} 6 \mathrm{MWT}$} & 0.8038 & 0.6461 \\
\hline \multicolumn{2}{|c|}{ Dist.-peak $V^{\prime} \mathrm{O}_{2} \mathrm{~mL} \cdot \mathrm{min}^{-1} \cdot \mathrm{kg}^{-1}$} & 0.4898 & 0.2399 \\
\hline \multicolumn{2}{|c|}{ Weight- $V^{\prime} \mathrm{O}_{2} \mathrm{~mL} \cdot \mathrm{min}^{-1} 6 \mathrm{MWT}$} & 0.7585 & 0.5754 \\
\hline
\end{tabular}

Ww: work of walking; $V^{\prime} \mathrm{O}_{2}$ : oxygen uptake; peak $V^{\prime} \mathrm{O}_{2}$ : maximum $V^{\prime} \mathrm{O}_{2}$ achieved during a bicycle CPET; Dist.: distance walked during the $6 \mathrm{MWT} ; V^{\prime} \mathrm{O}_{2} 6 \mathrm{MWT}$ :

RER, heart rate and $\mathrm{O}_{2}$ pulse. With the exception of two initially faster patients, the speed of walk was constant throughout the 6MWT. These results are in keeping with the notion that the 6MWT corresponds to a submaximal and sustainable aerobic effort $[1,2]$. In the present study, the RER remained below 1 during the entire $6 \mathrm{MWT}$, and the Borg dyspnoea score only moderately increased. This may be related to the fact that PAH patients already hyperventilate, both at rest and at exercise, in spite of decreased respiratory muscle strength [16-18]. In this context, exercising below the anaerobic threshold may prevent rapid exhaustion and unbearable dyspnoea caused by additional ventilatory burden of lactic acidosis. Conversely, PAH patients present with relatively high anaerobic threshold expressed as per cent of $V^{\prime} \mathrm{O}_{2}$ peak [19], allowing them to exercise at submaximal levels while remaining in aerobic conditions.

COOPER [20] introduced the 12-min running test as a surrogate for cumbersome maximum $V^{\prime} \mathrm{O}_{2}\left(V^{\prime} \mathrm{O}_{2}\right.$, max $)$ determinations in athletes. In that study on 115 young soldiers, the distance run

\begin{tabular}{|c|c|c|c|}
\hline \multirow[t]{2}{*}{ TABLE 2} & \multicolumn{3}{|c|}{$\begin{array}{l}\text { Comparison of ventilatory variables, arterial } \\
\text { oxygen saturation }\left(\mathrm{Sp}, \mathrm{O}_{2}\right) \text {, heart rate and } \mathrm{O}_{2} \\
\text { pulse achieved during the last minute of a } 6 \text {-min } \\
\text { walk test }(6 \mathrm{MWT}) \text { and a cardiopulmonary } \\
\text { exercise test }(\mathrm{CPET}) \text { in } 20 \text { patients with } \\
\text { pulmonary arterial hypertension }\end{array}$} \\
\hline & 6MWT & CPET & $p$-value \\
\hline$V^{\prime} \mathrm{O}_{2} \mathrm{~mL} \cdot \mathrm{min}^{-1} \cdot \mathrm{kg}^{-1}$ & $14.2 \pm 0.6$ & $12.9 \pm 0.7$ & 0.0542 \\
\hline$V^{\prime} \mathrm{O}_{2} \mathrm{~mL} \cdot \mathrm{min}^{-1}$ & $978 \pm 68$ & $900 \pm 71$ & 0.1076 \\
\hline$V^{\prime} \mathrm{CO}_{2} \mathrm{~mL} \cdot \mathrm{min}^{-1}$ & $881 \pm 65$ & $1024 \pm 85$ & 0.0195 \\
\hline RER & $0.90 \pm 0.02$ & $1.15 \pm 0.02$ & 0.00001 \\
\hline$V^{\prime} E \mathrm{~L} \cdot \mathrm{min}^{-1}$ & $46.0 \pm 3.3$ & $53.6 \pm 3.9$ & 0.0095 \\
\hline Heart rate beats $\cdot \min ^{-1}$ & $119 \pm 4$ & $135 \pm 4$ & 0.0010 \\
\hline $\mathrm{Sp}, \mathrm{O}_{2} \%$ & $76 \pm 4$ & $86 \pm 3$ & 0.0006 \\
\hline$V^{\prime} E / V^{\prime} \mathrm{CO}_{2}$ at $A T$ & $50.5 \pm 2.3$ & $48.7 \pm 2.1$ & 0.0996 \\
\hline $\mathrm{O}_{2}$ pulse $\mathrm{mL} \cdot$ beat $^{-1}$ & $8.5 \pm 0.6$ & $7.0 \pm 0.6$ & 0.0009 \\
\hline \multicolumn{4}{|c|}{$\begin{array}{l}\text { Data are presented as mean } \pm \mathrm{SE} \text {, unless otherwise stated. } V^{\prime} \mathrm{O}_{2} \text { : oxygen uptake; } \\
\mathrm{V}^{\prime} \mathrm{CO}_{2} \text { : carbon dioxide output; RER: respiratory exchange ratio; } V^{\prime} \mathrm{E} \text { : minute } \\
\text { ventilation; } \mathrm{Sp}, \mathrm{O}_{2} \text { : arterial oxygen saturation measured by pulse oximetry; AT: } \\
\text { anaerobic threshold. }\end{array}$} \\
\hline
\end{tabular}

in 12 min correlated well to $V^{\prime} \mathrm{O}_{2}$,max measured during treadmill exercise test, with a correlation coefficient of 0.9 , allowing for the derivation of a predicted $V^{\prime} \mathrm{O}_{2}$, max by the equation: $22.36 \times \mathrm{km}-11.29 \mathrm{~mL} \cdot \mathrm{kg}^{-1} \cdot \mathrm{min}^{-1}$. It has since been repeatedly shown that $V^{\prime} \mathrm{O}_{2}$,max, or $V^{\prime} \mathrm{O}_{2}$,peak, is correlated to the maximum average running or walking speed, and that this holds true for athletes as well as for patients with heart failure or chronic respiratory insufficiency and whether the tests consist of 12min running or 6-min walking.

In the present study, the correlation between the distance walked in $6 \mathrm{~min}$ and peak $V^{\prime} \mathrm{O}_{2}$ amounted to 0.49 , which is at the lower limit of reported in previous studies in patients with cardiac or respiratory diseases [2], including PAH patients [19]. This may be explained by variable body dimensions and locomotor skill.

In the present study, the correlation between $\mathrm{Ww}_{\mathrm{w}}$ and $V^{\prime} \mathrm{O}_{2}$,peak was much higher than that of the distance walked and $V^{\prime} \mathrm{O}_{2}$,peak, confirming a previous report on the importance of body weight [12]. Conversely, the determination of a true $V^{\prime} \mathrm{O}_{2}$, max, defined by the levelling off of $V^{\prime} \mathrm{O}_{2}$ between the final two exercise work rates [2] was not possible in the present study on severely symptomatic PAH patients. This could have altered the correlation to the average walking speed. However, peak $V^{\prime} \mathrm{O}_{2}$ was measured at RER $>1.1$ and, thus, closely reflected maximum aerobic capacity [2]. It is also noteworthy that $\mathrm{W}_{\mathrm{w}}$ was better correlated to the maximum $V^{\prime} \mathrm{O}_{2}$ achieved during the 6MWT than during the CPET, suggesting that the former is a more realistic estimate of the aerobic capacity in $\mathrm{PAH}$ patients.

The recent advent of portable spirometry devices has allowed direct real-time measurements of ventilatory variables during the 6MWT. In normal elderly subjects and in patients with heart failure, the plateau $V^{\prime} \mathrm{O}_{2}$ reached during a $6 \mathrm{MWT}$ has been shown to be lower than $V^{\prime} \mathrm{O}_{2}$, max or $V^{\prime} \mathrm{O}_{2}$,peak measured during a standard CPET [4-6]. In patients with COPD, the $V^{\prime} \mathrm{O}_{2}$ 
during the 6MWT has been reported to be equal to the $V^{\prime} \mathrm{O}_{2}$,peak measured during a CPET [7]. In that study, $V^{\prime} \mathrm{E} / V^{\prime} \mathrm{CO}_{2}$ and RER were lower during the 6MWT than during the CPET [7]. This result is in keeping with previous reports of later onset and less severe lactic acidosis at the same level of load during walking, compared with cycling exercise in COPD and heart failure [21, 22].

In the present study, the $V^{\prime} \mathrm{O}_{2}$ during the 6MWT tended to be higher than the $V^{\prime} \mathrm{O}_{2}$,peak achieved during a CPET, with definitely lower RER and ventilatory equivalents. A first possible explanation for this apparently paradoxical finding could have been a too-short CPET, less than the recommended average $10 \mathrm{~min}$ duration necessary for maintenance of a linear relationship between $V^{\prime} \mathrm{O}_{2}$ and work rate, which could have been the cause of earlier lactic acidosis [2]. The $V^{\prime} \mathrm{O}_{2}$ kinetics are indeed markedly slower in $\mathrm{PAH}$ patients than in normal subjects [16]. The steady state $V^{\prime} \mathrm{O}_{2}$ achieved in the $\mathrm{PAH}$ patients after $3 \mathrm{~min}$ of walking corresponds to the previously reported delay to stabilise $V^{\prime} \mathrm{O}_{2}$ at a given workload [16]. The chosen triangular profile of $10 \mathrm{~W} \cdot \mathrm{min}^{-1}$ of the CPET usually applied to patients with severe cardiac or respiratory disease $[16,19,21,22]$ may, thus, be inappropriate and lead to an underestimation of aerobic capacity in PAH patients.

Another possible explanation may be that more muscles are used for work during a 6MWT than during a CPET. As $V^{\prime} \mathrm{O}_{2}$, max is typically achieved by exercise that involves only half of total body musculature, aerobic exercise capacity is essentially determined by maximum cardiac output [2]. However, in untrained subjects, leg muscle mass used for cycling may be insufficient to achieve a maximum cardiac output response. The maximum aerobic capacity in untrained subjects is usually $10-20 \%$ higher during a treadmill than during a bicycle CPET [23]. Treadmill exercise tests compared with bicycle exercise tests are associated with lower lactate, RER and heart rate [24]. In addition, it is possible that in PAH, as in heart failure, the maximum muscle $\mathrm{O}_{2}$ extraction would be decreased, making $V^{\prime} \mathrm{O}_{2}$, $\max$ or $V^{\prime} \mathrm{O}_{2}$, peak relatively more muscle-mass dependent [18]. This explanation could account for the same or even slightly higher $V^{\prime} \mathrm{O}_{2}$ with relatively lower ventilation, $\mathrm{CO}_{2}$ output and heart rate during the $6 \mathrm{MWT}$ observed in PAH patients in the present study.

During the $6 \mathrm{MWT}, \mathrm{Sp}_{1} \mathrm{O}_{2}$ stabilised at lower values than achieved during the CPET in $\mathrm{PAH}$ patients. These results are in keeping with previous reports in COPD patients during shuttle walking tests [21] or 6MWT [25]. Patients with PAH frequently present with a decreased arterial oxygenation which is essentially explained by a decreased mixed venous oxygenation in the presence of well-preserved ventilation/ perfusion distributions at rest and at exercise [26]. Therefore, lower $\mathrm{Sp}_{\mathrm{p}} \mathrm{O}_{2}$ during the $6 \mathrm{MWT}$ in $\mathrm{PAH}$ patients is likely explained by a lower mixed venous partial pressure of $\mathrm{O}_{2}$ because of improved $\mathrm{O}_{2}$ extraction as compared with CPET.

In conclusion, the present results suggest that the 6-min walk test is a more realistic test for the determination of the aerobic exercise capacity than a standard incremental bicycle cardiopulmonary exercise test in patients with pulmonary arterial hypertension and, as such, more likely to be sensitive to therapeutic interventions.

\section{REFERENCES}

1 American Thoracic Society. ATS statement: guidelines for the six-minute walk test. Am J Respir Crit Care Med 2002; 166: 111-117.

2 Fleg JL, Pina IL, Balady GJ, et al. Assessment of functional capacity in clinical and research applications: an advisory from the Committee on Exercise, Rehabilitation, and Prevention, Council on Clinical Cardiology, American Heart Association. Circulation 2000; 102: 1591-1597.

3 Galie N, Seeger W, Naeije R, Simonneau G, Rubin LJ. Comparative analysis of clinical trials and evidence-based treatment algorithm in pulmonary arterial hypertension. $J$ Am Coll Cardiol 2004; 43: Suppl. 12, 81S-88S.

4 Riley M, McParland J, Stanford CF, Nicholls DP. Oxygen consumption during corridor walk testing in chronic cardiac failure. Eur Heart J 1992; 13: 789-793.

5 Faggiano P, D'Aloia A, Gualeni A, Lavatelli A, Giordano A. Assessment of oxygen uptake during the 6-minute walking test in patients with heart failure: preliminary experience with a portable device. Am Heart J 1997; 134: 203-206.

6 Kervio G, Carre F, Ville NS. Reliability and intensity of the six-minute walk test in healthy elderly subjects. Med Sci Sports Exerc 2003; 35: 169-174.

7 Troosters T, Vilaro J, Rabinovich R, et al. Physiological responses to the 6-min walk test in patients with chronic obstructive pulmonary disease. Eur Respir J 2002; 20: 564-569.

8 Barst RJ, Langleben D, Frost A, et al. Sitaxsentan therapy for pulmonary arterial hypertension. Am J Respir Crit Care Med 2004; 169: 441-447.

9 Simonneau G, Galie N, Rubin LJ, et al. Clinical classification of pulmonary hypertension. J Am Coll Cardiol 2004; 43: Suppl. 12, 5S-12S.

10 Guyatt GH, Sullivan MJ, Thompson PJ, et al. The sixminute walk: a new measure of exercise capacity in patients with chronic heart failure. Can Med Assoc J 1985; 132: 919-923.

11 Borg GA. Psychophysical bases of perceived exertion. Med Sci Sports Exerc 1982; 14: 377-381.

12 Chuang ML, Lin IF, Wasserman K. The body weightwalking distance product as related to lung function, anaerobic threshold and peak $\mathrm{VO}_{2}$ in COPD patients. Respir Med 2001; 95: 618-626.

13 Wasserman K, Hansen JE, Sue DY, Whipp BJ. Principles of Exercise Testing and Interpretation. 3rd Edn. Baltimore, MD, USA, Lippincott Williams \& Wilkins, 1999; pp. 143164.

14 Winer BJ, Brown DR, Michels KM. Statistical Principles in Experimental Design, 3rd Edn. New York, USA, Mc GrallHill, 1991; pp. 220-283.

15 Bland JM, Altman DG. Measuring agreement in method comparison studies. Stat Methods Med Res 1999; 8: 135-160.

16 Sun XG, Hansen JE, Oudiz RJ, Wasserman K. Exercise pathophysiology in patients with primary pulmonary hypertension. Circulation 2001; 104: 429-435.

17 Meyer FJ, Lossnitzer D, Kristen AV, et al. Respiratory muscle dysfunction in idiopathic pulmonary arterial hypertension. Eur Respir J 2005; 25: 125-130. 
18 Naeije R. Breathing more with weaker respiratory muscles in pulmonary arterial hypertension. Eur Respir J 2005; 25: 6-8.

19 Deboeck G, Niset G, Lamotte M, Vachiéry J-L, Naeije R. Cardiopulmonary exercise testing in pulmonary arterial hypertension and in congestive heart failure. Eur Respir J 2004; 23: 747-751.

20 Cooper $\mathrm{KH}$. A means of assessing maximal oxygen intake. Correlation between field and treadmill testing. JAMA 1968; 203: 135-138.

21 Palange P, Forte S, Onorati P, Manfredi F, Serra P, Carlone S. Ventilatory and metabolic adaptations to walking and cycling in patients with COPD. J Appl Physiol 2000; 88: 1715-1720.

22 Page E, Cohen-Solal A, Jondeau G, et al. Comparison of treadmill and bicycle exercise in patients with chronic heart failure. Chest 1994; 106: 1002-1006.
23 Miyamura M, Honda Y. Oxygen intake and cardiac output during treadmill and bicycle exercise. J Appl Physiol 1972; 32: 185-188.

24 Miles DS, Critz JB, Knowlton RG. Cardiovascular, metabolic, and ventilatory responses of women to equivalent cycle ergometer and treadmill exercise. Med Sci Sports Exerc 1980; 12: 14-19.

25 Poulain M, Durand F, Palomba B, et al. 6-min walk testing is more sensitive than maximal incremental cycle testing for detecting oxygen desaturation in patients with COPD. Chest 2003; 123: 1401-1407.

26 Dantzker DR, D'Alonzo GE, Bower JS, Popat K, Crevey BJ. Pulmonary gas exchange during exercise in patients with chronic obliterative pulmonary hypertension. Am Rev Respir Dis 1984; 130: 412-416. 